\title{
Ewelina Zając
}

Uniwersytet Łódzki

\section{Przechodzenie ojko- i anojkonimów w obrębie klas toponimicznych - na materiale $\mathrm{z}$ powiatu tureckiego}

Praca w głównej mierze opiera się na współczesnym materiale nazewniczym $\mathrm{z}$ terenu powiatu tureckiego, który zebrano podczas badań terenowych w latach 2010-2012 w ramach przygotowywanej rozprawy doktorskiej. Uwzględniono także materiały źródłowe: archiwalne mapy topograficzne powiatu tureckiego z roku 1936, Słownik geograficzny Królestwa Polskiego i innych krajów słowiańskich [1880-1895] oraz Badania nazw topograficznych S. Kozierowskiego [Kozierowski 1914-1939].

Nomina propria, czyli nazwy własne, swoją proweniencję zawdzięczają apelatywom, czyli wyrazom pospolitym. Pogląd taki ugruntowany został jeszcze przez uczonych z kręgu młodogramatyków. Nawet W. Taszycki mówi: „Materiał onomastyczny wywodzi się genetycznie z apelatywnego, co już dawno stwierdzono” [Taszycki 1963: 9]. Powtórzyć można również, iż: ,apelatywa sięgają swymi pierwocinami epoki prasłowiańskiej, nazwy własne miejscowe zaś datują się dopiero od XVI wieku" [Smoczyński 1962: 63]. Dodać trzeba jednak, iż nie wszystkie nazwy własne, zwłaszcza miejscowe, powstały od wyrazów pospolitych, mogły także zostać utworzone od innych imion własnych. Jednak nie najważniejsze jest samo pochodzenie nazwy, a jej struktura, wywodzona od apelatywu geograficznego. Struktura nazwy własnej z jednej strony wyjaśnia jej etymologię, a z drugiej pozwala na zaklasyfikowanie onimu do odpowiedniego typu, klasy [Jurkowski 1964: 103].

O tym, jaki jest wzajemny stosunek miedzy nomen proprium a nomen appellativum pisze m.in. R. Zawiliński: ,[... ] nazwy były pierwotnie imionami pospolitemi (appellativa) a nie własnemi (propria) i oznaczały treść lub właściwość przedmiotu nazywanego" [Zawiliński 1909: 51]. K. Dejna również pisze: „Nazwy miejscowe czy terenowe należą do odrębnej pod względem semantyczno-morfologicznym klasy rzeczowników, a mianowicie do nazw (imion) własnych (nomina propria). Przeciwstawiane tej klasie rzeczowniki pospolite wyrażają pojęcia, na których treść składają się cechy istotne, przysługujące całemu szeregowi przedmiotów jednorodnych względnie pojęciom oderwanym. Nazwy zaś własne 
posiadają treść indywidualną i spełniają funkcję wyróżniania jednych przedmiotów czy zjawisk tego samego typu od drugich, nie wskazując na ich właściwości (cechy)" [Dejna 1956: 108]. Jednak szczególny charakter nazw własnych polega także na specjalnym wyborze wyrazów, pierwiastków, afiksów i złożeń oraz na długotrwałości ich użycia w języku [Jurkowski 1964: 103].

Najprostszym i najczęstszym sposobem powstania nazwy własnej z wyrazu pospolitego jest indywidualizacja znaczeniowo-językowa apelatywu bez pomocy środków formalno-językowych [ibidem: 105], czyli wyraz pospolity, oznaczający gatunek, staje się wyrazem oznaczającym jednostkę, np. góra : Góra. Bardzo ważny jest również fakt, że nomen proprium i nomen appellativum mogą funkcjonować równolegle obok siebie.

Między nazwą własną a wyrazem pospolitym jest bardzo cienka granica i często nie wiadomo czy wyraz pospolity posiada już ustaloną funkcję onomastyczną. Zdarza się tak zwłaszcza w mikrotoponimii, bowiem jeśli ktoś nazywa las Lasem i łąkę Łąką, to nie wiadomo, czy ma on na myśli jeden z wielu lasów (łąk) czy też konkretne miejsce w terenie. Można więc zaobserwować dość szybki proces wymiany wyrazu pospolitego na nazwę własną, zaznaczając jednak, że oba te wyrazy mogą występować w języku obok siebie, np. las : Las, łąka : Łąka.

Nazwy własne powstają także w wyniku przesunięcia znaczenia wyrazu pospolitego. Jeśli na danym polu rosły lipy to często pole to nazywa się Lipy, Lipki, mimo iż drzewa te $\mathrm{z}$ czasem wycięto i przekształcono teren, to samą nazwę dla pola się zachowuje.

Wiele nazw to również twory indywidualne, tzw. przenośnie topograficzne, których wyjaśnienie sprawia wiele trudności [Ostromęcka-Frączak 1970: 45-57].

M. Buczyński [Buczyński 1988: 73-76] pisał już o zmianach nazw geograficznych, jednak miał tu na myśli zmianę nazwy miejscowej. Wyróżnił on trzy typy zmian: 1) spontaniczne, kiedy zmienia się element krajobrazu, właściciel osiedla, sposób życia mieszkańców, 2) oddające walkę między formami powstałymi spontanicznie a utworzonymi odgórnie oraz 3) urzędowe, narzucone odgórnie. Typ zmian spontanicznych zauważyć można również w nazwach terenowych, zwłaszcza na wsiach. Pole nazywane niedawno Po Bartosiku obecnie nosi nazwę Filipczakowe, ponieważ ziemię nabył nowy właściciel o nazwisku Filipczak, stary określnik stał się zbyt mało wyrazisty, dlatego doszło do zmiany.

Zasób i funkcja nazw terenowych często podlegają zmianom w obrębie danej wspólnoty. Współcześnie daje się zauważyć tendencję do nazywania terenów (niewielkich obszarów) zamieszkiwanych przez ludzi, zwłaszcza terenów wiejskich, na których osiedla się ludność z miast. Są to najczęściej tereny leśne położone $\mathrm{z}$ daleka od centrum wsi. Jednak w materiale nazewniczym, który zebrałam, zauważa się proces odwrotny. Wsie, które dawniej pełniły funkcję odrębnych autonomicznych jednostek, obecnie są częściami, przysiółkami innych wsi. W tym wypadku charakter nazwy się nie zmienia, wciąż są to ojkonimy, zmienia się jedynie ich funkcja. Oto przykłady: Alinia - gw. alińa (często ańe. 
líia), część wsi Małoszyna (na starych mapach pojawia się także forma Amelin; gm. Władysławów); Bagna - gw. bogna, część miasta Tuliszków (obecnie ulica Gromadzka; gm. Tuliszków); Bielawki - gw. bilofkí, część wsi Nowy Czachulec (gm. Kawęczyn); Bolesławów - gw. bolesuavuf, część wsi Mariantów (gm. Władysławów); Boleszczynek - gw. boleščynek, część wsi Bądków Drugi (gm. Przykona); Budki - gw. butkí, część wsi Ogorzelczyn i miasta Tuliszków (obecnie ulica Zaremby, wcześniej wieś Budki Ogorzelskie; gm. Tuliszków); Budy Psarskie - gw. budy psarsk'e, część wsi Psary (gm. Przykona); Dębocha - gw. dymboxa, część wsi Russocice (gm. Władysławów); Dominików - gw. dominikuf, część wsi Warenka (gm. Turek); Emerytka - gw. emerytka, część wsi Mariantów (gm. Władysławów); Halinów - gw. ұalinuf, część wsi Bierzmo (gm. Brudzew); Ignacew - gw. iignacef, część wsi Kamionka, wcześniej wieś Ignacowo (gm. Władysławów); Kaczki Mostowe - gw. kačǩi mostove, część wsi Kaczki Średnie (gm. Turek); Kaliska - gw. kaliska, część wsi Tarnowa (gm. Tuliszków); Kilania - gw. kilańa, część wsi Wrząca (gm. Turek); Kordownia - gw. kordovńa, część wsi Kuźnica Janiszewska (gm. Brudzew); Kunegundowo - gw. kunegundovo, część wsi: Ogorzelczyn, Sarbicko (gm. Tuliszków); Lęg Wielki gw. uygg velkí, część wsi Sarbice (gm. Przykona); Lowiguz - gw. uovigus, część wsi Grzymiszew, wcześniej wieś Łowikuz (gm. Tuliszków); Mechniówka - gw. mexńufka, część wsi Zagaj, kiedyś wieś Miechniówka lub Machniówka; Mikolajew - gw. ḿikouaief, część wsi Międzylesie (gm. Władysławów); Nowa Wieś - gw. novo veś, część wsi Bierzmo (gm. Brudzew); Nowe Józinki - gw. nove inuźink'i, część wsi Sarbicko (gm. Tuliszków); Orzepów - gw. unožepuf, część wsi Kowale Pańskie (gm. Kawęczyn); Paluszek - gw. palušek, część wsi Gadowskie Holendry (gm. Tuliszków); Piaski - gw. ṕoskí, część miasta Tuliszków (obecnie ulica Piaskowa; gm. Tuliszków); Piorunów - gw. ṕorunuf, teren należący do wsi Wyszyna (gm. Władysławów); Podarek - gw. podarek, część wsi Czajków (gm. Dobra); Przemysławów - gw. pšemysuavuf, część wsi Międzylesie (gm. Władysławów); Sacały - gw. sacauy, część wsi Kuźnica Janiszewska (gm. Brudzew); Siewieruszki Małe - gw. śeveruški maue, teren wsi Wojciechów (gm. Kawęczyn); Siewieruszki Wielkie - gw. śeveruš̌ki v́elké , teren wsi Wojciechów (gm. Kawęczyn); Stawiska - gw. staviiska, część wsi Nowy Czachulec (gm. Kawęczyn); Stawki Potworowskie - gw. stofki potforoskee, część wsi Potworów (gm. Dobra); Szadłowice - gw. šaduovíce, część wsi Słodków, wcześniej wieś Sadłowice (gm. Turek); Utrata - gw. untrata, część wsi Felicjanów (gm. Władysławów); Wandów - gw. vanduf, część wsi Mariantów, wcześniej wieś Wandowo (gm. Władysławów); Wiktorów - gw. viktoruf, część wsi Cichów (gm. Brudzew); ̇̇dżarki - gw. ̌̌žarkí, część wsi Polichno (gm. Władysławów); Żuchała

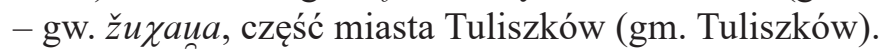

Na badanym terenie doszło także do przeobrażenia dwu odrębnych dawniej wsi w jedną, tym samym wcześniejsze dwie nazwy przybrały jedną wspólną, np.: Psary Kościelne - gw. psary kośćelne i Psary Mostowe - gw. psary mostove 
tworzą obecnie wieś Psary (gm. Przykona); Poroże Nowe - gw. porože nove i Poroże Stare - gw. porože stare to obecnie jedna wieś Poroże (gm. Malanów); również w jedną wieś Gadowskie Holendry przeobraziły się wcześniejsze wsie

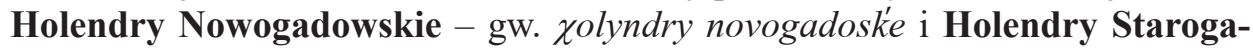

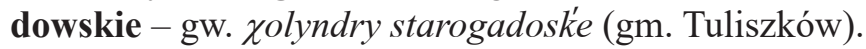

W powiecie tureckim, na terenie gmin Przykona, Turek, Władysławów i Brudzew, w wyniku wieloletniej odkrywkowej działalności kopalni węgla brunatnego „Adamów”, doszło do wysiedlenia mieszkańców wielu wsi i tym samym do likwidacji miejscowości. Niektóre z nich zniknęły z map administracyjnych powiatu, a ich nazwy nie są już nigdzie odnotowywane, chociaż są jeszcze używane, jak np.: Bartkówka - gw. bartkufka, obecnie na tym terenie znajduje się zbiornik wodny (gm. Przykona); Piotrów - gw. ṕotruf, obecnie okolice kopalni (gm. Przykona); Stanisławów - gw. stańisuavuf, obecnie teren kopalni (gm. Przykona). $Z$ budowy słowotwórczej nazw wynika, że można je zaliczyć do grupy nazw dzierżawczych, świadczy o tym sufiks -ów, -ówka. Na omawianym terenie, czyli we wschodniej części Wielkopolski przeważają nazwy z sufiksem -ów, ale pojawiają się również nazwy zakończone na -owo//-ewo dla oznaczenia miejsc niezamieszkanych [Demartin 1965: 17].

Zdarzyło się i tak, że nazwy miejscowości, które zostały zlikwidowane, obecnie nie funkcjonują w użyciu, są jedynie zapisane na mapie topograficznej z 1936 r. oraz w Stowniku Królestwa Polskiego... Są to następujące nazwy: Bisztora - gw. bišstora (gm. Tuliszków); Bogusławice - gw. bogusuavice (gm. Tuliszków); Bronisławów - gw. brońisuavuf (gm. Tuliszków); Kaleniec - gw. kaleńec (gm. Tuliszków); Gozd - gw. gost (gm. Tuliszków); Kozia Góra - gw. koźo gura (gm. Tuliszków); Rzadkwice - gw. žatkfice (gm. Przykona); Tury - gw. tury (gm. Władysławów).

Kolejnym zjawiskiem, świadczącym o tym, że nomina propria są kategorią nazw, które wciąż powstają i zanikają, jest zmiana charakteru nazw z ojkonimów na anojkonimy. Nazwy obiektów zamieszkanych dawniej przez człowieka stały się obecnie anojkonimami i nazywają miejsca fizjograficzne niezamieszkane przez ludzi. Są to: Goleszczyzna - gw. golě̌čyzna, pole we wsi Brudzew (gm. Brudzew); Józefów - gw. ìuzefuf, las we wsi Dzierżązna (gm. Turek); Józinki - gw. inuźinkí, pole leżące między wsią Krępa a miastem Tuliszków (gm. Tuliszków); Karpaty - gw. karpaty, pola i lasy należące do wsi Międzylesie (gm. Władysławów); Olędry - gw. uolyndry, pole we wsi Żdżary (gm. Kawęczyn); Sierpik - gw. śerpik, pole we wsi Wielopole (gm. Tuliszków); Słomów Górny - gw. suumuv gurny, obecnie pole, teren pokopalniany (gm. Przykona).

Między nomen appellativum a nomen proprium można wymienić jeszcze formę pośrednią, o której wspomina S. Hrabec [1968: 184-328], są to apelatywa toponomastyczne. To wyrazy pospolite o cechach morfologicznych, słowotwórczych imion własnych, które zbudowane zostały na wzór typowych nazw miejscowych w danej okolicy [ibidem: 288]. Za klasyfikacją S. Hrabca wynotowuję nazwy własne $\mathrm{z}$ zebranego przeze mnie materiału, które swe pochodzenie wy- 
wodzą od apelatywów toponomastycznych: Biedajew/Biedajów - gw. bidai b'edaiuf, część wsi Strachocice Kolonia (gm. Dobra); Biedaszew - gw. bidašef, część wsi Ciemień (gm. Kawęczyn); część wsi: Chylin, Natalia (gm. Władysławów); Biedaszków - gw. bidaškuf, część wsi Wyszyna (gm. Władysławów); Czekaj - gw. čekai, pole we wsi Mikulice (gm. Dobra); Widok - gw. vidok, pole we wsi Wróblina (gm. Tuliszków); Wydrzygrosz - gw. vyḍ̌ygroš, część wsi

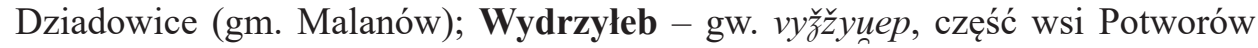

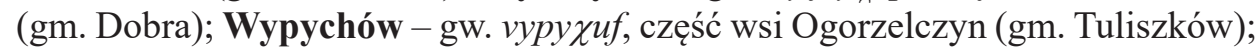
Wypychówek - gw. vypyұuvek, część wsi: Gadowskie Holendry, Sarbicko (gm. Tuliszków); pola we wsi Tarnowa (gm. Tuliszków); Zlodziejów - gw. zuoźceiuf, część wsi Kawęczyn (gm. Kawęczyn). Dodać należy, że wspomniane apelatywa toponomastyczne stały się zapewne podstawą do utworzenia nazw miejscowych, np. Dziadowice - gw. żadovice, wieś (gm. Malanów).

Kolejnym przykładem płynności między wyrazem pospolitym a nazwą własną jest obecność w naszej kulturze nazw przeniesionych. „Podstawą takiego zastosowania już raz istniejącej nazwy musi być najpierw proces przejścia nomen proprium do apelatywum, a potem zastosowanie tego apelatywum - będącego pierwotnie imieniem własnym - znowu jako nomen proprium" [ibidem: 325]. Również i takie nazwy można przytoczyć z zebranego materiału $\mathrm{z}$ terenu powiatu tureckiego, np.: Korea - gw. koreina, pole we wsi Kwiatków (gm. Brudzew); Paryż - gw. paryš, pole we wsi Bibianna (gm. Malanów); Warszawa - gw. varšava, część wsi Skarbki (gm. Władysławów); pole we wsi Kiszewy (gm. Tuliszków); Warszawka - gw. varšafka, potocznie o wsi Stawki (gm. Władysławów); Wietnam - gw. v́etnam, określenie wsi Wietchinin (gm. Turek).

Bardzo cienka granica między wyrazami pospolitymi a nazwami własnymi jest widoczna szczególnie w nazwach terenowych. Są one najczęściej w stadium powstawania, ustalania się, dlatego często bywa tak, że jeden obiekt posiada dwie lub więcej nazw, które powiązane są ze sobą morfologicznie lub których nie można uszeregować według morfologicznego porządku rozwojowego [Śmiech 1983: 37]. Nierzadkim zjawiskiem jest pokrywanie się nazwy terenowej z wyrazem pospolitym, zarówno kiedy wyraz jest nazwą pospolitą jakiegoś pojęcia oraz nazwą własną jednego z desygnatów, np. Ląki - gw. uụki łąki we wsi Chrząblice (gm. Brudzew); łąki we wsi: Ewinów, Żeroniczki (gm. Przykona); łąki we wsi Grabieniec (gm. Turek); łąki we wsi Kuny (gm. Władysławów), a także kiedy wyraz pospolity jest nazwą obiektu, który nie jest desygnatem pojęcia tego wyrazu, np. Łąka - gw. un lite mogą pełnić funkcję nazwy własnej tylko w określonym środowisku, jeśli nazywany obiekt jest jedynym tego rodzaju obiektem na tym terenie i nie istnieje inna potrzeba nazywania go, lub też jeśli istnieje kilka takich samych obiektów, nazwanych już wcześniej inaczej [ibidem: 40]. Za W. Śmiechem można powtórzyć, że: „w funkcji nazw terenowych występują wyrazy pospolite odnoszące się głównie do konkretnych obiektów terenowych" [ibidem: 43]. 
Kategorią nazw terenowych, będących ciągle w stadium rodzenia się, powstawania, są nazwy przyimkowe, które określają położenie nazywanego obiektu. Kiedy nazwa się utrwali - a dodać trzeba, że nazwy terenowe używane są przez członków małych społeczności, dobrze znających teren - najczęściej zachodzi proces odrzucenia członu utożsamiającego. $\mathrm{Z}$ materiału zebranego na terenie powiatu tureckiego znaczną część zajmują nazwy w postaci wyrażeń przyimkowych, np.: Do Granic - gw. do grańic, pole we wsi Skęczniew (gm. Dobra); Do Kanału - gw. do kanauu, pole we wsi Podłużyce (gm. Brudzew); Kole Rowu - gw. kole rovu, pole we wsi Trzymsze (gm. Przykona); Kole Stawu - gw. kole stovu, łąka we wsi Boleszczyn (gm. Przykona); Koło Dębu - gw. kouo dymbu, pole we wsi Podłużyce (gm. Brudzew); Koło Filipa - gw. kouo filípa, pole we wsi Czajków (gm. Dobra); Na Działku - gw. na źzouku, pole we wsi Psary (gm. Przykona); Na Foluszu - gw. na folušu, pole we wsi Chrapczew (gm. Dobra); Po Dudku - gw. po dutku, pole we wsi Janów (gm. Brudzew); Po Dziedzicu - gw. po ź ’́ łąka we wsi Józefina (gm. Przykona); Przy Lesie - gw. pšy leśe, pole we wsi Kowale Księże (gm. Turek); Przy Leszku - gw. pšy lešku, część wsi Dąbrowa (gm. Przykona); pole we wsi Posoka (gm. Przykona); Za Rowkiem - gw. za rofkim, pole we wsi Zygmuntówek (gm. Malanów); pole we wsi Przykona (gm. Przykona); Za Ryśkiem - gw. za ryśk'im, droga we wsi Młyniska (gm. Przykona). Z czasem można także zaobserwować przekształcenie się nazwy w postaci wyrażenia przyimkowego w rzeczownik, np. Zabrodzie - gw. zabroźe, kiedyś część miasta Turek, w której znajdował się dworek i fabryka (gm. Turek); Zagóry - gw. zagury, pole we wsi Chylin (gm. Władysławów); Zamłynie - gw. zamuyńe, część wsi Kwiatków (gm. Brudzew); pole we wsi Psary (gm. Przykona). To kolejny proces, świadczący o tym, że nazwy własne, zwłaszcza nazwy terenowe, to kategoria in statu nascendi.

Omówiwszy przedstawiony materiał z powiatu tureckiego, wysnuto wnioski, które można ująć w pięciu punktach:

1. Miejscowe i terenowe nazwy własne to kategoria nazw własnych, które wciąż powstają, ale także i zanikają. Z przytoczonego materiału zaobserwować można, że na terenie powiatu tureckiego zachodzi proces zanikania nazw miejscowych. Wiąże się to działalnością odkrywkową kopalni węgla brunatnego. Dochodzi również do włączania dawnych wsi w skład obecnych większych miejscowości, stają się one przysiółkami, częściami wsi.

2. Zauważa się także zmianę charakteru nazwy z ojkonimu na anojkonim, nazwy dawnych wsi nazywają obecnie pola, łąki, lasy, czyli obiekty fizjograficzne, niezamieszkane przez człowieka.

3. Przechodzenie nazw pomiędzy klasami toponimicznymi - ojko- i anojkonimami - ma charakter kulturowy, a nie językowy, ponieważ zmiany nie dotyczą systemu. Charakter nazw się nie zmienia, zmianie ulega jedynie ich funkcja. 
4. Nazwy własne, czyli nomina propria, swe pochodzenie zawdzięczają wyrazom pospolitym, ale są też przypadki, kiedy nazwy własne pochodzą od innych imion własnych, mogą to być nazwy deminutywne lub od nazw osobowych.

5. Nazwy własne, zarówno miejscowe, jak i terenowe, wciąż będą powstawały i zanikały, ma na to wpływ wiele czynników kulturowych, gospodarczych i społecznych. Nazwy nigdy nie były i nie są jednoznacznym i autorytatywnym odzwierciedleniem wszystkich procesów osadniczych.

\title{
Bibliografia
}

Słownik geograficzny Królestwa Polskiego i innych krajów słowiańskich, 1880-1895, t. I-XIV, Warszawa.

Buczyński Mieczysław, 1988, Polityczne, socjalne i kulturowe uwarunkowania zmian nazw geograficznych, Ogólnopolska Konferencja Onomastyczna, Poznań, 73-76.

Dejna Karol, 1956, Terenowe nazwy śląskie, „Onomastica”, t. II, z. 1, 103-126.

Demartin Adam, 1965, Oboczność sufiksalna -ov : - 'ev w nazwach miejscowych Wielkopolski, „Slavia Occidentalis”, t. XXV, 15-29.

Hrabec Stefan, 1968, Polskie apelatywa toponomastyczne, „Rozprawy Komisji Językowej Łódzkiego Towarzystwa Naukowego", t. XIV, 284-328.

Jurkowski Marian, 1964, Terminy geograficzne a nazwy własne, „Poradnik Językowy”, 101-122.

Kozierowski Stanisław, 1914-1939, Badania nazw topograficznych, t. I-VIII, Poznań.

Ostromęcka-Frączak Bożena, 1970, Nazwy miejsc w gwarach polskich, „Rozprawy Komisji Językowej Łódzkiego Towarzystwa Naukowego", t. XVI, 45-57.

Smoczyński Paweł, 1962, Nomina appellativa i propria we wzajemnym oddziaływaniu słowotwórczym, „Biuletyn Polskiego Towarzystwa Językoznawczego”, t. XXI, 61-82.

Śmiech Witold, 1983, Stosunek polskich nazw terenowych do wyrazów pospolitych, [w:] Kazimierz Rymut (red.), Geografia nazewnicza, Wrocław, 37-51.

Taszycki Witold, 1963, Stosunek onomastyki do innych nauk humanistycznych, „Onomastica”, t. VIII, 1-18.

Zawiliński Roman, 1909, Nazwy geograficzne i ich znaczenie, „Poradnik Językowy”, 49-51.

\author{
Ewelina Zając
}

\section{Shifting of oyco- and anoyconymes between toponimic classes - on the material from Turek district}

(Summary)

The topic of the article are modern oyco- and anoyconymes of Turek district collected during field exploration. Historical material was also included to show changes taking place in toponimic classes over the years. Local and field names are categories of proper names that continue to appear but also disappear. Basing on the materials included in this work, the process of disappearance of local names can be observed as well as inclusion of smaller villages into larger settlements. Thus the character of the name remains the same, it is still an oyconym, but its function changes. The 
reverse process can also be observed, meaning the change of name character from oyconyme to anoyconyme, as the names of former villages are currently used for physiographic uninhabited objects. Processes related to creation of topographic names and shifting of oyco- and anoyconymes are supported with rich naming material. The article concludes by statement that mutual shifting of nomen apellativum and nomen proprium has cultural, not linguistic character, as the changes do not affect the system; character of names does not change, but their function does.

Słowa kluczowe: oikonimy, anoikonimy, toponomastyka.

Key words: oyconymes, anoyconymes, toponomastics. 